\title{
ACESSO À JUSTIÇA E VIOLÊNCIA DOMÉSTICA E FAMILIAR CONTRA AS MULHERES: AS PERCEPÇÕES DOS OPERADORES JURÍDICOS E OS LIMITES PARA A APLICAÇÃO DA LEI MARIA DA PENHA *
}

Wânia Pasinato

\section{RESUMO}

ESTE ARTIGO BASEIA-SE NOS RESULTADOS DA PESQUISA "VIOLÊNCIA CONTRA A MULHER E ACESSO À JUSTIÇA", QUE TEVE COMO OBJETIVO REFLETIR SOBRE A EFETIVIDADE DA APLICAC̣ÃO DA LEI N. 11.340/2006 (LEI MARIA DA Penha) (CEPIA/Fundaçāo Ford) E SEUS EFEITOS PARA A AMPLIACCÃO DO ACESSO À JUSTIÇA PARA AS MULHERES EM SITUAÇÃO DE VIOLÊNCIA. EMPIRICAMENTE, A PESQUISA Se realizou como estudos de caso em Porto Alegre, Recife, Salvador, Rio de Janeiro e São Paulo. Foram ENTREVISTADOS 64 OPERADORES DO DIREITO E OUTROS PROFISSIONAIS QUE ATUAM COM A APLICAÇĀO DA LEI. A PESQUISA PERMITIU ANALISAR AS DISTANNCIAS ENTRE OS DISPOSITIVOS LEGAIS, AS PRÁTICAS PROFISSIONAIS E AS ROTINAS INSTITUCIONAIS DE APLICAÇĀO DA LEGISLAÇÃO FORTEMENTE ORIENTADAS POR ESTEREÓTIPOS DE GÊNERO ENTRE OUTROS. CONCLUI-SE QUE NA BRECHA ENTRE O FORMAL E A PRÁTICA SE REPRODUZEM AS DISCRIMINAC̣ŌES CONTRA AS MULHERES QUE LIMITAM SEUS DIREITOS DE ACESSO À JUSTIÇA E SUSTENTAM SEU NĀO RECONHECIMENTO COMO SUJEITO DE DIREITOS.

\section{PALAVRAS-CHAVE}

LEI MARIA DA PENHA; VIOLÊNCIA DOMÉSTICA E FAMILIAR; MULHERES EM SITUAÇĀO DE VIOLÊNCIA; GÊNERO, ACESSO À JUSTIÇA.

\section{ABSTRACT}

THIS ARTICLE IS BASED ON THE RESEARCH FINDINGS ON "VIOLENCE AGAINST WOMEN AND ACCESS TO JUSTICE", WHICH AIMED TO REFLECT ON THE EFFECTIVENESS OF THE APPLICATION OF LAW NO. 11.340/2006 (MARIA DA PENHa LAW) (CEPIA/Ford FOUNDATION) aNd ITS EFFECTS EXPANDING ACCESS TO JUSTICE FOR WOMEN IN SITUATIONS OF VIOLENCE. EMPIRICALLY, THE RESEARCH WAS CONDUCted as CASE studies in PoRto Alegre, Recife, Salvador, Rio de Janeiro and Sao Paulo. 64 OF LAW OPERATORS WERE INTERVIEWED AND OTHER PROFESSIONALS WHO WORK WITH THE APPLICATION OF THE LAW. THE SURVEY ALLOWED US TO ANALYZE THE GAP BETWEEN THE LEGAL PROVISIONS, PROFESSIONAL AND INSTITUTIONAL ROUTINES APPLYING THE HEAVILY ORIENTED LEGISLATION FOR GENDER STEREOTYPES PRACTICES AMONG OTHERS. IT IS CONCLUDED THAT THE GAP BETWEEN THE FORMAL AND THE PRACTICE REPRODUCE DISCRIMINATION AGAINST WOMEN THAT LIMIT THEIR RIGHTS TO ACCESS TO JUSTICE AND SUPPORT THEIR NON-RECOGNITION AS A SUBJECT OF RIGHTS.

\section{KEYWORDS}

MARIA da PENHA LAW; DOMESTIC VIOLENCE; WOMEN LIVING ON VIOLENCE SITUATION; GENDER; ACCESS TO JUSTICE. 


\section{INTRODUÇÃO}

A aprovação de leis especiais para o enfrentamento da violência baseada no gênero tem sido uma estratégia adotada pelos movimentos de mulheres em vários países para criar garantias formais de acesso à justiça e a direitos para mulheres em situação de violência. Este processo de mudanças legislativas tem seus avanços registrados particularmente a partir da década de 1990 no contexto de duas importantes convenções internacionais de direitos das mulheres: a Conferência para Eliminação de Todas as Formas de Discriminação contra as Mulheres - CEDAW (1979) e a Convenção Interamericana para Prevenir, Punir e Erradicar a Violência contra a Mulher - Convenção de Belém do Pará (1994). Além das Conferências Internacionais de Direitos Humanos (Viena, 1993), População (Cairo, 1994), Mulheres (Beijing, 1995) que colocaram em relevo os direitos das mulheres como direitos humanos e as estratégias para seu reconhecimento e promoção.

Os movimentos feministas brasileiros não estiveram alheios a esses debates. Além de o Estado brasileiro ter assinado e ratificado os acordos internacionais, a participação de militantes feministas brasileiras no contexto internacional das Nações Unidas e da Organização de Estados Americanos, e a articulação interna de diferentes grupos de mulheres e feministas somaram forças decisivas para lutar contra o déficit histórico no acesso à justiça e à cidadania que afeta as mulheres em todo o País.

Um marco nesse processo foi a Constituição de 1988 com o reconhecimento formal de vários direitos da cidadania para as mulheres. Os avanços na situação das mulheres brasileiras, suas participações política, social e econômica são bastante visíveis na sociedade e estão expressos em indicadores nacionais. ${ }^{1}$ No entanto, ainda persiste uma grande lacuna entre os direitos formais e os direitos de fato, excluindo da cidadania largas parcelas da população feminina.

Vários balanços já foram realizados sobre esse contexto legislativo nas últimas décadas (BARSTED, 2011, 2011a; PANDJIARJIAN, 2006; RODRIGUES; CORTÊS, 2006), com mudanças que podem ser resumidas nas palavras de Pandjiarjian, que afirma:

Do ponto de vista normativo, a grande maioria dessas mudanças foi bastante positiva e representou um avanço no tratamento do tema, mas algumas não tiveram impacto, outras tiveram, até mesmo, um impacto especialmente negativo no enfrentamento jurídico da problemática. ...ainda são gritantes os limites entre a lei e o acesso aos direitos, na prática, para as mulheres vítimas de violência. (PANDJIARJIAN, 2006, p. 78)

Visando contribuir com essa temática, a CEPIA realizou projeto que teve como objetivo refletir sobre a efetividade da aplicação da Lei n. 11.340/2006 (Lei Maria da Penha) e seus efeitos para a ampliação do acesso à justiça para as mulheres em situação de violência. O ponto de partida para este projeto de pesquisa foi a constatação 
de que as mulheres no Brasil ainda enfrentam um déficit em termos de reconhecimento social do seu pleno direito à justiça e que interfere com as práticas discriminatórias que prevalecem nas instituições policiais e judiciais.

De acordo com o relatório "Progresso das Mulheres/2003-2010" (BARSTED; PITANGUY, 2011), a aprovação da Lei Maria da Penha representa a força do movimento feminista brasileiro em sua contínua busca de espaços de diálogo com os poderes da República em prol dos direitos das mulheres. Na redação dessa lei, um consórcio de ONGs exerceu uma inovadora ação legislativa apresentando aos Poderes Executivo e Legislativo uma proposta de texto que foi aprovada praticamente sem alterações. Esse consórcio também manteve uma ação de advocacy em todo o percurso de tramitação do projeto que deu origem à Lei Maria da Penha (BARSTED, 2011).

A lei em questão é reconhecida como um marco para o processo histórico de construção e reconhecimento dos direitos das mulheres como direitos humanos no Brasil. Aclamada pela Organização das Nações Unidas como uma das leis mais avançadas no enfrentamento da violência contra as mulheres no mundo (UNWOMEN, 2011), essa legislação contempla medidas judiciais e extrajudiciais adotando uma concepção ampla de acesso à justiça e a direitos a partir da perspectiva de gênero. Por sua abrangência, o texto legislativo é também considerado um conjunto de políticas públicas para o enfrentamento da violência baseada no gênero, cuja aplicação integral depende do compromisso do Executivo, do Judiciário e do Legislativo nas esferas do governo federal, dos estados e municípios.

A aprovação social da Lei Maria da Penha tem sido demonstrada em pesquisas de opinião que foram realizadas desde sua entrada em vigor, em 2006 (ARTIGO 19, 2015). Uma das mais recente, realizada pelo DataSenado (2013), mostrou que 99\% das mulheres entrevistadas já ouviram falar da Lei Maria da Penha. Apesar das proporções animadoras e que indicam a importância desse processo de conscientização da sociedade, outra pesquisa realizada no mesmo período (Instituto Patrícia Galvão/Data Popular, 2013) chamou a atenção para o conhecimento sobre o conteúdo da lei, mostrando que enquanto $98 \%$ de entrevistado(a)s declararam conhecer a lei, apenas 9\% disseram saber muito e $23 \%$ razoavelmente bem/bastante sobre seu conteúdo.

Por um lado, esses números refletem o investimento que vem sendo feito em campanhas educativas e uma crescente conscientização das mídias que colocam em destaque os casos de violência contra as mulheres, e sobre a existência de uma legislação que precisa ser cumprida. Por outro lado, os números também alertam para parte dos problemas que as mulheres enfrentam para ter acesso à justiça, revelando lacunas no acesso à informação clara e suficiente sobre os mecanismos de proteção e assistência previstas na legislação.

Um efeito dessa maior visibilidade da lei e da violência doméstica e familiar tem sido a crescente demanda por informações, o que repercutiu na procura dos serviços, levando a uma permanente pressão sobre os governos estaduais e municipais para a 
criação de novos serviços e na capacitação de pessoal para atendimento especializado. Alguns resultados já podem ser vistos com a ampliação no número de delegacias da mulher, juizados de violência doméstica e familiar, promotorias e defensorias especializadas (SPM, 2011).

No entanto, apesar dos investimentos financeiros e técnicos promovidos pela Secretaria de Políticas para Mulheres (SPM) por meio do Pacto Nacional de Enfrentamento à Violência Contra as Mulheres e do Programa Mulher, Viver sem Violência priorizando a criação de novos equipamentos, a capacitação profissional e a edição de normas técnicas, manuais, resoluções e enunciados voltados a aprimorar o atendimento e melhorar o acesso à justiça para as mulheres em situação de violência doméstica e familiar a realidade dos atendimentos permanecem muito aquém do esperado em termos de especialização requerida na perspectiva de gênero e respeito aos direitos das mulheres (OBSERVE, 2011; MARTINS; CERQUEIRA; MATOS, 2015).

As pesquisas têm mostrado que a inexistência e/ou a inoperância desses serviços muitas vezes não contribuem e mesmo constituem obstáculos para que as mulheres possam ter acesso a seus direitos (OBSERVE, 2011; PASINATO, 2012). Falta de recursos materiais, de recursos humanos e despreparo das equipes são alguns dos problemas enfrentados. Outros problemas são a ausência de políticas sociais nos setores de saúde, habitação, educação, geração de renda e trabalho, assistência social e previdência social, entre outras, com a devida adequação dessas políticas para atender as mulheres em situação de violência doméstica e familiar; a dificuldade que os profissionais enfrentam para o trabalho articulado, intersetorial e multidisciplinar - o trabalho "em rede" - com uma persistente mentalidade de que cada serviço deve funcionar como uma "microrrede", trazendo para dentro de seu espaço o atendimento multidisciplinar, multiplicando o atendimento emergencial, com uma atuação fragmentada, descontínua, que permite poucos encaminhamentos, muitas vezes limitados por uma visão assistencialista ou de acesso a benefícios provisórios, mas que pouco ou nada contribuem para dar respostas efetivas para as mulheres e seu processo de fortalecimento e acesso a seus direitos.

Conhecedora desse contexto pontuado por avanços e resistências à mudança, a CEPIA realizou a pesquisa sobre os limites da aplicação da Lei Maria da Penha, abordando o acesso à justiça a partir de indicadores sobre a institucionalidade das estruturas necessárias para implementação da Lei Maria da Penha no sistema de segurança e justiça, a existência e condições de funcionamento dos serviços e as percepções dos operadores jurídicos sobre a lei, sobre violência doméstica e familiar e sobre as mulheres que procuram os serviços e demandam seus direitos por meio da aplicação da lei. Neste artigo, considerando os limites de sua extensão, optou-se por apresentar um extrato dos resultados desse último conjunto de indicadores, uma vez que as percepções dos operadores jurídicos revelaram importantes aspectos sobre os obstáculos para o acesso à justiça das mulheres em situação de violência doméstica e familiar. 


\section{Os estudos De CASO: PROCEDIMENTOS METODOlÓgiCOS}

Considerando o contexto anteriormente mencionado e reconhecendo os avanços ocorridos no Brasil nas duas últimas décadas, o desafio que se coloca para a efetivação da cidadania das mulheres refere-se à necessidade de diminuir a distância entre o progresso legislativo e o efetivo acesso à justiça. Nesta pesquisa, o tema do acesso à justiça é tratado pela dupla abordagem que considera, de um lado, a conquista tardia de uma cidadania formal para as mulheres, cujo marco anteriormente referido é o iniciado com a Constituição de 1988; e, por outro lado, a resistência cultural e institucional para reconhecer a violência doméstica e familiar como crime para os quais devem ser aplicadas as medidas de punição, prevenção e proteção previstas na lei.

A combinação dessas duas abordagens contribui para uma melhor compreensão da resistência institucional e cultural à aplicação da Lei Maria da Penha e uma avaliação mais completa do quanto o novo paradigma definido na Lei Maria da Penha tem sido incorporado nas práticas das instituições e dos operadores do direito. Por essa razão, o foco principal desta pesquisa são os agentes encarregados de aplicar a Lei Maria da Penha, considerando-se crucial conhecer sua visão em relação à violência doméstica e familiar e a Lei Maria da Penha, suas resistências, os entraves que enfrentam e as propostas de aprimoramento que apresentam. No entender da CEPIA, essa perspectiva, ainda pouco estudada, deve ser privilegiada.

O objetivo geral desta pesquisa foi contribuir para a ampliação e o aperfeiçoamento do acesso à justiça pelas mulheres em situação de violência doméstica e familiar e a boa implementação da Lei Maria da Penha. ${ }^{2}$ Utilizou-se metodologia qualitativa baseada em estudos de caso que foram orientados por indicadores para avaliar os avanços dos compromissos institucionais com a aplicação da Lei Maria da Penha, as condições de funcionamento dos serviços existentes, a percepção dos operadores do direito sobre a legislação e os limites que encontram para sua atuação. ${ }^{3}$ Os indicadores também abordam a percepção sobre a violência e as mulheres que recorrem às instâncias policiais e judiciais, buscando verificar o reconhecimento de sua cidadania. A construção dos indicadores foi realizada a partir da revisão de bibliografia sobre a Lei Maria da Penha e sobre o acesso à justiça. Para todas as etapas desta pesquisa foi adotada a perspectiva de gênero, compreendendo que os sistemas político e normativo de cada sociedade não são neutros, e contribuem para a reprodução da desigualdade entre homens e mulheres.

Os estudos de caso foram realizados em cinco capitais (Porto Alegre, Recife, Rio de Janeiro, Salvador e São Paulo), selecionadas a partir de critérios que permitissem avaliar algum potencial de mudança em favor da aplicação dessa legislação que introduziu um conjunto de novas atribuições para os serviços de segurança e justiça, criando estruturas capazes de aplicar as medidas previstas, levando em conta suas especificidades. Entre os critérios de seleção: a) a existência de uma rede "mínima” de atendimento especializado para mulheres em situação de violência doméstica 
e familiar; ; b) a existência de órgãos de coordenação responsáveis pela institucionalidade desses serviços; e c) novas experiências que pudessem ser consideradas como "práticas promissoras" e indicativas de mudanças na aplicação da Lei Maria da Penha. ${ }^{5}$

O material empírico consistiu em 64 entrevistas com delegada(o)s de polícia, promotora(e)s de justiça, defensora(e)s pública(o)s, juíza(e)s, entre outro(a)s profissionais considerados relevantes em cada contexto analisado. Os profissionais foram selecionados entre aqueles responsáveis pela aplicação da Lei Maria da Penha nos órgãos especializados, bem como os órgãos de coordenação na Polícia Civil, Ministério Público, Defensoria Pública e Poder Judiciário de cada um dos estados selecionados. ${ }^{6}$ As entrevistas foram realizadas a partir de roteiros semiestruturados e quando autorizadas foram registradas em áudio e posteriormente transcritas para análise. Em cada localidade, o estudo resultou em um relatório descritivo-analítico reunindo os resultados das entrevistas, análise da bibliografia pertinente, além de consulta a documentos institucionais que ajudaram a contextualizar a existência e o funcionamento dos diferentes serviços e programas.

O desenvolvimento da pesquisa valeu-se de técnicas de pesquisa qualitativa, sem a pretensão de ser um estudo exaustivo sobre cada localidade. Os resultados permitem oferecer um relato sobre "o estado da arte" da aplicação da Lei Maria da Penha em cada uma das capitais selecionadas no momento em que se realizava a pesquisa de campo. ${ }^{7}$ Para dar amplitude a esses resultados, as análises comparativas valem-se dos resultados de outros estudos já realizados no país. ${ }^{8}$

\section{I SObre ACESSO À JUSTIÇA E VIOLÊNCIA CONTRA AS MULHEReS}

Para esta pesquisa, o acesso à justiça entende-se a partir da articulação de três dimensões: uma normativo-formal, com o reconhecimento dos direitos pelo Estado e sua formalização em leis; outra que se refere à existência de mecanismos e estratégias para tornar o acesso à justiça formal em acesso real, com sua efetividade por meio da organização, administração e distribuição da justiça; e a terceira dimensão envolve as condições de cada cidadão e cidadã para se reconhecer como sujeito de direitos e acionar as leis na proteção de seus direitos. Essas dimensões envolvem o compromisso dos Estados com a aprovação de leis que promovam a garantia dos direitos, a revisão ou afastamento daquelas leis e normas vigentes e que ferem ou confrontam os direitos em questão, a criação de mecanismos e condições para que cidadãos e cidadãs possam acionar as leis e exercitar seus direitos e a aplicação efetiva das leis com decisões judiciais justas tanto para a sociedade quanto para os indivíduos, segundo as regras do processo legal, resultando em medidas efetivas e eficazes para a reparação dos direitos violados (CAPPELLETTI; GARTH, 1988; SOUZA SANTOS, 1996).

Mesmo que todos esses obstáculos possam ser removidos ou seus efeitos minorados, não haverá garantia de que o acesso à justiça será universal e efetivo para todos os que dela necessitem. Aspectos sociais e culturais precisam ser também observados 
nesse processo de reconhecimento de direitos e de sua realização, incluindo aspectos educacionais, status social, meio social onde a pessoa vive - que valem tanto para a(o)s cidadã(o)s que recorrem ao sistema de justiça para fazer valer seus direitos quanto para os servidores e profissionais do Direito que atuam nesse sistema ${ }^{9}$ - acesso à informação sobre direitos, sobre como acionar a justiça e a localização geográfico-espacial dos tribunais. Também aspectos internos ligados ao formalismo dos tribunais, o excesso de trâmites e a linguagem jurídica inacessível para leigos constituem barreiras que contribuem para aumentar não só a distância simbólica entre os tribunais e a sociedade, mas também a desconfiança da população em relação a essas instituições e seus representantes (CAPPELLETTI; GARTH, 1988; SOUZA SANTOS, 1996).

Tratando da violência contra as mulheres, esses processos tornam-se ainda mais complexos pelos fatores históricos e culturais que consideram a violência assunto privado, naturalizam suas práticas e responsabilizam as mulheres tanto pelas causas da violência quanto pelas consequências de sua denúncia.

Somam-se, ainda, os fatores "internos", subjetivos e que se relacionam ao contexto da violência (doméstico e familiar) e as relações de afeto entre vítimas e agressores, o que faz com que as mulheres carreguem muitas dúvidas e medos junto à decisão de denunciar ou não a violência que sofrem (PASINATO, 2012; JUBB, 2010). Essa é uma especificidade da violência baseada em gênero que frequentemente é posta de lado quando se pensam as políticas públicas para seu enfrentamento. Esse é também um indicador de que essas políticas ainda não incorporam a perspectiva de gênero em sua formulação e se desenvolvem numa lógica tradicional de gênero que contribui para a manutenção dessa “ordem institucional de gênero" (MILOSAVLJEVIC, 2007) que mantém as barreiras entre o público e o privado, identifica e aprisiona as mulheres aos papéis de mães e esposas e converte as diferenças entre homens e mulheres em desigualdades sociais, hierarquizando os atributos do masculino e do feminino numa métrica que sempre desfavorece as mulheres no acesso e exercício de seus direitos.

Nesse sentido, para este estudo, entende-se que a ampliação do acesso à justiça para as mulheres em situação de violência doméstica e familiar depende da criação das estruturas previstas na legislação e na Política Nacional de Enfrentamento à Violência com suas premissas de rede e intersetorialidade, da formação e capacitação dos profissionais e operadores do direito para compreensão das especificidades de gênero, mas depende também que essa estrutura seja modelada a partir da transversalização de gênero nas políticas e organização das instituições involucradas com a construção da cidadania e da igualdade de gênero.

\section{A Lei Maria da Penha e o acesso À Justiça na Percepção dos OPERADORES DO DIREITO}

A caracterização da Lei Maria da Penha e das novidades que trouxe ao contexto jurídico 
nacional já foi realizada em vários trabalhos (PASINATO, 2008; CAMPOS, 2011, entre outros). Entre as mudanças a mais emblemática é o reconhecimento da violência baseada no gênero como violação de direitos humanos (art. $6^{\circ}$ ). A incorporação dessa definição não é apenas um recurso linguístico de alinhamento com o discurso internacional de proteção de direitos das mulheres, mas representa a adoção de um novo paradigma para orientar as respostas que o Estado deve dar para esse problema social.

Tratar a violência doméstica e familiar contra a mulher como violação de direitos humanos, por um lado, implica o reconhecimento das mulheres como sujeitos, cujos direitos são universais e inalienáveis e devem ser protegidos pela lei e promovidos pelas políticas públicas. Por outro lado, implica ampliar a compreensão desse fenômeno social para além dos limites impostos pelo binômio da criminalização-vitimização (IZUMINO, 2003; SOARES, 2002) sobre o qual se ancorou, até meados da década de 1990, o debate sobre o reconhecimento da violência contra as mulheres como problema social no Brasil (PASINATO, 2008) e cuja lógica estava baseada numa visão restrita de punição e penalização dos agressores (SOARES, 2002).

A superação dessa visão deve-se, em grande parte, à aprovação pela Assembleia Geral da Organização dos Estados Americanos (OEA) da Convenção para Prevenir, Punir e Erradicar a Violência contra a Mulher (1994) que aponta a necessária mudança nas relações de gênero que só poderá ser alcançada com o reconhecimento dos direitos das mulheres como um todo e o consequente enfrentamento das desigualdades sociais entre homens e mulheres. Nesse contexto, a incorporação da expressão “violência baseada no gênero", presente no art. 5, é outro componente importante da Lei Maria da Penha. Seu uso repercute no interior do sistema normativo nacional o reconhecimento de que a violência doméstica e familiar contra a mulher não será mais aceita como componente "natural” e "admissível” das relações entre homens e mulheres.

Na mesma linha e de forma complementar, a substituição da expressão "mulheres vítimas de violência” pela expressão "mulheres em situação de violência” vem reforçar o reconhecimento de que a violência de que trata essa lei é um fenômeno sociocultural que pode ser modificado por meio de políticas para prevenir novos atos, proteger os direitos das mulheres e coibir as práticas de violência nas diferentes formas que passam também a ser classificadas pela Lei Maria da Penha (CAMPOS; CARVALHO, 2011; PASINATO, 2012).

De forma coerente com essa mudança, a lei é inserida num sistema de proteção e promoção dos direitos das mulheres baseado numa política integral de enfrentamento à violência contra as mulheres que contempla também políticas de assistência que contribuam para o fortalecimento das mulheres e a igualdade de gênero.

A legislação também introduziu mudanças na intervenção que deve ser realizada pelas instituições de segurança e justiça, com novas atribuições para a polícia, alterações 
na organização judiciária para o funcionamento dos juizados especializados e na esfera de atuação da Defensoria Pública e do Ministério Público. Grande parte das atribuições previstas na lei não chega a se caracterizar como novidade, pois se referem às atividades de polícia judiciária. Mas a Polícia Civil também passa a ser responsável pelo registro das medidas protetivas de urgência e atender a necessidades urgentes de deslocamento das mulheres principalmente para garantir sua integridade física nos casos em que a residência ainda é compartilhada com o agressor.

Além do domínio técnico para execução das tarefas, essas atividades precisam também levar em consideração as especificidades da violência baseada no gênero. Nesse sentido, a lei também recomenda a capacitação da Polícia Civil e das demais instituições de segurança pública - Polícia Militar, Corpo de Bombeiros e Guarda Municipal - para que estejam sensibilizados e preparados para intervir em casos de violência doméstica e familiar.

Na esfera do Judiciário, a lei recomenda aos Tribunais de Justiça Estaduais e do Distrito Federal que criem os Juizados de Violência Doméstica e Familiar para aplicação exclusiva e integral da Lei Maria da Penha. Nesse caso, trata-se não apenas de criar nova seção, mas dotá-la de estrutura necessária para a competência “civil e criminal para o processo, o julgamento e a execução das causas decorrentes da prática de violência doméstica e familiar contra a mulher" (art. 14). Essa estrutura inclui a composição das equipes multidisciplinares que atuem de forma a assessorar os magistrados na tomada de decisões, particularmente aquelas relacionadas com as medidas protetivas.

As medidas previstas na Lei Maria da Penha abordam o enfrentamento da violência doméstica e familiar contra a mulher de forma integral, com intervenções para punir os agentes responsáveis pela violência, proteger os direitos das mulheres e promover seu acesso à assistência e a seus direitos, e a prevenção da violência por meio de campanhas e processos de mudança cultural baseados no rompimento dos padrões de relacionamento entre homens e mulheres em favor da igualdade de gênero. Diante da morosidade judicial e da ausência de respostas no âmbito da justiça criminal, as medidas protetivas de urgência são colocadas no centro das intervenções dos operadores do direito (OBSERVE, 2011). Essas medidas de natureza extrapenal expressam o reconhecimento da condição de vulnerabilidade em que se encontram as mulheres em situação de violência nas relações domésticas e familiares.

Na perspectiva de gênero, a proteção à mulher será ainda mais integral se o mesmo juiz puder construir uma compreensão mais ampla sobre esse complexo contexto das relações domésticas e familiares (OBSERVE, 2010), mas não há consenso sobre a implementação da dupla competência prevista para as varas/juizados e a tendência tem sido fragmentar as medidas criando distinções entre medidas de proteção à integridade física e aquelas de natureza cautelar relacionadas à situação familiar e patrimonial. Analisando essas medidas: 
... as medidas protetivas não são instrumentos para assegurar processos. O fim das medidas protetivas é assegurar direitos fundamentais, evitando a continuidade da violência e das situações que a favorecem. E só. Elas não são, necessariamente, preparatórias de qualquer ação judicial. Elas não visam processos, mas pessoas. (LIMA, 2011, p. 329)

$\mathrm{Na}$ aplicação do quarto conjunto de indicadores elaborados para esta pesquisa, o(a)s entrevistado(a)s foram interrogados a respeito de suas percepções sobre as mudanças introduzidas pela Lei Maria da Penha, as formas de sua aplicação, sobre suas compreensões a respeito da violência definida pela lei e sobre as mulheres que atendem cotidianamente. Vale relembrar que o objetivo era compreender como essas percepções contribuem para facilitar ou dificultar o acesso das mulheres à justiça.

Do conjunto de resultados obtidos, para este artigo, foram selecionados três temas tratados nas entrevistas: as medidas protetivas, as diferentes formas de violência definidas pela lei e a representação criminal em casos de lesão corporal. Todos estes temas estão perpassados pela percepção sobre as mulheres atendidas e a situação de violência em que se encontram no momento em que acionam a justiça.

A dimensão comparativa está embutida na forma de apresentação dos resultados. Essa opção se baseia no fato de que não foram encontradas diferenças substantivas na forma como o(a)s entrevistado(a)s nas cinco capitais se comportaram no tratamento dos temas apresentados. Quando relevante, foram incluídas citações ou mencionadas capitais de forma ilustrativa. Mais informações encontram-se no relatório final da pesquisa, conforme mencionado nas notas ao final deste artigo.

\section{I AS MEDIDAS PROTETIVAS DE URGÊNCIA}

Os entendimentos acerca das medidas protetivas são um bom exemplo dos desafios colocados para a aplicação integral da lei. Na leitura dos relatórios das cinco capitais é possível apontar um consenso: as medidas protetivas previstas na Lei Maria da Penha são reconhecidas como a grande inovação trazida pela legislação. A possibilidade de dar uma resposta mais ágil para as mulheres, proteger sua integridade física e resguardar os direitos de seus filhos e dependentes foi mencionada como prioridade em todas as capitais. Na opinião de uma entrevistada, as medidas protetivas garantem também o direito de a mulher permanecer em sua casa enquanto o agressor é afastado da residência: "A medida protetiva é mais justa com as mulheres porque quem sai de casa é o agressor e não ela” (Delegada de Polícia).

Apesar desse entusiasmo, as DEAMs e os Juizados não possuem bons dados estatísticos sobre essas medidas, de forma que não é possível saber quantas são solicitadas e quantas são deferidas. ${ }^{10}$ De acordo com as entrevistas realizadas nas cinco capitais, as medidas aplicadas com mais frequência são aquelas que limitam as formas de contato entre vítimas e agressores: ordem de afastamento da residência comum, proibição 
de frequentar os mesmos lugares que a mulher (escola, trabalho etc.) e proibição de contato (telefônico ou mensagens eletrônicas por qualquer meio). A proteção se estende também a dependentes. Com essas medidas, estabelecem-se limites para o agressor e cria-se certa rede de proteção para as mulheres que ficam livres do assédio e da ameaça constantes, que assim podem ter alguma tranquilidade para refletir sobre os encaminhamentos que poderão buscar para sair da situação de violência. Outras medidas que são também aplicadas se referem à separação conjugal, ação de guarda e alimentos. Não há uma forma única de aplicação dessas medidas, mas prevalece o entendimento de que são medidas cautelares apenas.

As medidas são solicitadas principalmente nas delegacias de polícia, mas podem também ser apresentadas por meio da Defensoria Pública. Em sua maior parte, a(o)s entrevistada(o)s afirmam que são deferidas, embora não se tenha números sobre esse movimento. Na polícia, há também preocupação em respeitar os prazos, com o envio dos documentos para o Judiciário dentro das 48 horas previstas pela lei. O cumprimento dos prazos é um dos pontos de discórdia observado nas entrevistas. Enquanto são apontadas falhas como a demora na apreciação e decisão por juíza(e)s, esta(e)s se queixam da precariedade dos relatos e da falta de evidências para embasar suas decisões. Há também demora em notificar as mulheres e seus agressores sobre a decisão judicial e não existem mecanismos para fazer o seguimento das medidas e saber se efetivamente as mulheres estão protegidas. ${ }^{11}$

De todos os problemas que foram apontados, o mais grave é a morosidade judicial e o consequente volume de processos que prescrevem sem decisões, de forma que muitas vezes as medidas protetivas acabam sendo a única decisão judicial que as mulheres conseguem obter:

... as medidas protetivas são um ganho e "são elas que seguram a Lei Maria da Penha...” dado o contexto de muitas prescrições. Neste sentido, A Vara se transformou em um órgão proferidor de medidas protetivas, não de sentenças. (Defensora Pública)

Como resposta isolada, há um risco identificado de as medidas protetivas perderem seu efeito, ainda que parte das pessoas entrevistadas assegure que as medidas são positivas para as mulheres e efetivamente garantem a proteção que necessitam:

Em relação às medidas protetivas, a nossa experiência é de que elas funcionam. O que acontece? Primeiro que havendo uma intervenção do Estado, para o homem que acredita que está agindo corretamente, ele tem uma sensação de que aquilo é mais sério, de que alguém está olhando por aquela mulher e por aquela família. [...]. (Promotora de Justiça) 
Uma das queixas entre juíza(e)s e promotora(e)s é a carência de elementos e a fragilidade de provas para embasar suas decisões na concessão das medidas protetivas, principalmente quando se trata de afastar o agressor da residência comum do casal. A situação de risco em que se encontra a mulher tem se apresentado como um imperativo para a solicitação e a apreciação judicial das medidas protetivas de urgência. Como dito, em geral, esta tem sido feita nas delegacias de polícia, no momento de registro da ocorrência policial. Nessas ocasiões, é comum que a vítima compareça sozinha à delegacia, assim como é frequente também que a violência tenha ocorrido em momentos em que o casal se encontrava sozinho, ou que tenha ocorrido na presença de filhos ou outros familiares que podem preferir não dar seu testemunho - por medo ou pela situação de dependência econômica em que se encontrem, pelos laços afetivos ou ainda pela crença de que em "briga de marido e mulher não se mete a colher".

Em síntese, o que ocorre é que as medidas protetivas devem ser solicitadas a partir da versão apresentada pelas mulheres e a recomendação que se faz é para que sua palavra seja valorizada. Para juíza(e)s acostumados a deliberar com base no contraditório, a ausência da versão do agressor ou de testemunhas pode dificultar a decisão ou mesmo torná-la inviável, resultando em seu indeferimento. Em alguns casos, solicitam o retorno do documento para as delegacias para pedir mais informações; em outros casos, esperam pela intervenção da equipe multidisciplinar e o laudo psicológico que produzirão. Seja qual for a alternativa adotada, consome tempo e faz com que, muitas vezes, o caráter de urgência se perca. No Rio de Janeiro, uma delegada afirmou que um pedido de medidas protetivas pode levar de 4 a 6 meses para ser analisado pelo juiz. ${ }^{12}$ Em São Paulo, embora o deferimento seja mais rápido, ele não é feito de forma automática, principalmente quando o(a) juiz(a) encontra dificuldade para analisar a situação e separar a proteção da mulher da proteção da família.

A(o)s entrevistada(o)s também indicaram a existência de falhas e de dificuldades de natureza processual que consideram não estar esclarecidas na lei. Por exemplo, com relação às medidas que se aplicam para a guarda de filhos e ações de alimentos, em algumas localidades encontra-se que são aplicadas como medidas cautelares, necessitando a instauração de uma ação de alimentos em Vara de Família, como ocorre em São Paulo, onde os pedidos de separação conjugal, guarda de filhos e alimentos são deferidos com validade de 30 dias. Após essa data, a mulher que tiver interesse em dar continuidade à ação deverá ingressá-la na Vara de Família.

Em Porto Alegre, as medidas são aplicadas com prazo de 6 meses, mas não foi possível saber se esse prazo se aplica a todas as medidas protetivas. Na Bahia, ao contrário, não se estabelece prazo para as medidas protetivas, inclusive para aquelas que determinam o afastamento do agressor do lar e a proibição de contato e, de acordo com um defensor público, existem medidas protetivas que estão em vigor há 2 anos sem que tenha havido decisão no processo criminal: 
Às vezes eu acho que se cria uma anomalia em que as medidas protetivas ficam às vezes vigorando por um longo período de tempo sem ter uma ação principal [...] hoje na Bahia já tem um provimento dizendo que as questões de direito de família só serão decididas pelo juiz da Vara de violência doméstica se houver acordo entre as partes, senão houver acordo fica restrita à ação penal. É aí que entra, na minha ótica, a questão da falta de efetividade, porque aqui fica muito tempo as medidas protetivas sendo válidas e não se decide direito material. E o direito material no caso é a prática de algum crime contra a mulher. [...] e para que isso fosse efetivado teria que ter a resposta do Estado [...] a medida protetiva fica muitas vezes regulando essa relação litigiosa que o direito material na verdade é o direito penal... muitas vezes há medidas de afastamento sendo que nem se analisou se aquela situação é crime ou não. Então eu acho que fica muito no limbo essa situação. (Defensor Público)

Outro problema colocado com relação a essas medidas foi a intimação tanto das vítimas quanto dos agressores. Nesse cenário, uma juíza observa:

... como magistrada [para mim] esse é um dos maiores pontos nevrálgicos de aplicação da lei, a intimação tem que ser rápida, a vítima tem que ser intimada rapidamente, o agressor também. Tenho vítima que está com a medida deferida já tem mais de dois meses, e se ele procurar ela eu posso configurar descumprimento de medida protetiva? Não, porque ele não estava cientificado. Como eu posso dizer que ele descumpriu algo se ele não foi cientificado? (Juíza de Direito)

Essa dificuldade de notificar vítimas e seus agressores tem sido traduzida como um "desaparecimento intencional" das mulheres, e tem levado a questionamentos sobre quem são as mulheres em situação de violência doméstica e familiar e seu reconhecimento como sujeito de direitos. Em Porto Alegre, Rio de Janeiro e São Paulo, uma opinião comum entre as policiais é que as medidas protetivas estão sendo banalizadas e que as mulheres usam e abusam dessas medidas que deveriam ser empregadas "apenas para aquelas que precisam".

Situações em que as mulheres chegam à delegacia requerendo o afastamento do agressor da casa ou afirmam querer a separação conjugal são percebidas pelas delegadas de polícia como uma forma de obter a separação rapidamente e sem passar pelas varas de família. Para isso, segundo as policiais, as mulheres mentiriam, inventariam histórias de ameaças para as quais não possuem provas. Expressões como "disque-separação" e "separação express", empregadas pelas policiais para se referir ao comportamento das mulheres, revelam o descrédito que essas profissionais atribuem a essas 
solicitações. Há também muita desconfiança em relação a outros setores, principalmente a Defensoria e advogados. Para as policiais, as mulheres estariam sendo orientadas pelos defensores a procurar a delegacia para registrar a queixa e pedir a medida protetiva, pois assim conseguiriam a separação mais rapidamente:

Então, por exemplo, o casal vive em conflito e a mulher quer separar, tem baixo poder aquisitivo não tem condição de constituir um advogado. Vai para a Defensoria Pública. Lá o que ela quer? Ela quer que o marido saia da casa. [Perguntam] "ele ameaça? "ah, ele ameaça, ele diz que vai me matar...", mas não é uma coisa que realmente coloca em risco. Então o que faz, se pede as tais medidas protetivas para que ele saia da casa...há uma banalização das medidas protetivas. (Delegada de Polícia)

Em síntese, embora reconhecidas como avanços, na prática, as medidas protetivas geram muitas críticas e insatisfações entre os profissionais e criam uma dinâmica de responsabilização entre todos: nas delegacias, se queixam do encaminhamento realizado pelas defensorias, nas defensorias acusam as policiais de fazer "corpo mole" e não providenciar a solicitação das medidas protetivas. Nas promotorias, observam que as mulheres chegam desinformadas e nos juizados, juízes e juízas queixam-se que recebem pouca informação nas peças policiais. Essas situações foram observadas em praticamente todas as capitais incluídas neste estudo e "evidenciam a falta de articulação entre os serviços e as dificuldades que ao final recaem sobre as mulheres que buscam esses serviços” (Relatório do Rio de Janeiro).

\subsection{A VIOLÊNCIA DOMÉSTICA E FAMILIAR E OS TIPOS DE VIOLÊNCIA ABRANGIDOS PELA LEI}

A percepção dos operadores do direito também mostra o que entendem por violência doméstica e familiar. A Lei Maria da Penha define cinco tipos de violência: física, psicológica, sexual, patrimonial e moral. Essas definições são um avanço do ponto de vista conceitual e da tentativa de sensibilizar os operadores do direito para o contexto em que a violência baseada no gênero ocorre. Ainda que nem todas as formas de violência ocorram sempre na mesma ação, também não é possível dizer que existe uma hierarquia entre elas. Uma mulher pode ser humilhada por anos a fio, ou viver sob intenso controle de sua vida e sofrer severos danos à sua autoestima e saúde mental, sem que seu agressor nunca cometa um único gesto de violência física.

No entanto, situações de violência física e sexual na maior parte das vezes envolvem ofensas morais e também ameaças e humilhações. Portanto, mais do que tentar enquadrar cada gesto ou ação num tipo penal específico, o operador deveria compreender as categorias de violência em conjunto e como caracterizam o exercício desigual de poder que é definidor da violência baseada no gênero.

As narrativas apresentadas pelas mulheres sobre a violência que sofreram apenas 
são reconhecidas a partir de sua classificação segundo os tipos penais e essa nem sempre é fácil, de forma que a demanda das mulheres fica muitas vezes sem efeito quando levada à polícia. A violência é mais facilmente reconhecida quando deixa marcas, ou seja, quando ocorrem as lesões corporais e também a violência sexual (PASINATO, 2012).

Quando questionados sobre essas categorias, as respostas dos operadores jurídicos mostram que, por exemplo, o entendimento da violência psicológica é feito de forma superficial, limitada aos tipos penais de ameaça, constrangimento ilegal e injúria, mas o registro dessa violência que não deixa "marcas visíveis" é dificultado pela falta de provas (PASINATO, 2012).

O reconhecimento da violência contra as mulheres como crime ainda é um obstáculo enfrentado por muitas mulheres que procuram as delegacias de polícia em todo o País. Embora a afirmativa pareça deslocada no tempo e no espaço, depois de 30 anos de denúncias e de campanhas para que essa violência seja objeto de criminalização e de políticas públicas, para muitos profissionais, sobretudo policiais, a violência doméstica e familiar continua a ser percebida como problema de natureza social, cuja solução não deveria ser encaminhada por meio da intervenção policial ou do sistema de justiça criminal.

\subsection{LESÕES CORPORAIS E A REPRESENTAÇÃO CRIMINAL}

As percepções sobre os tipos de violência tratados pela Lei Maria da Penha e denunciados pelas mulheres conectam-se com o tema da representação criminal nos casos de lesões corporais. A representação criminal foi tema de divergência entre os aplicadores da Lei Maria da Penha levado a julgamento pelo Supremo Tribunal Federal (STF). Em fevereiro de 2012, na mesma decisão que afirmou a constitucionalidade da Lei Maria da Penha e renovou a proibição da aplicação dos dispositivos da Lei n. 9.099/95 aos casos de violência doméstica e familiar, o STF decidiu que o crime de lesão corporal deverá ser tratado como ação pública incondicionada.

Nas entrevistas realizadas em fins de 2012 e início de 2013, encontrou-se que, apesar da decisão, o tema não se encontrava pacificado entre os operadores do direito, gerando opiniões divergentes sobre sua aplicação e sua finalidade.

Das cinco capitais analisadas nesta pesquisa, apenas em Porto Alegre a decisão ainda não vinha sendo aplicada no final de 2012, período em que a pesquisa foi realizada. Segundo um dos entrevistados, a decisão ainda não havia sido publicada e, por isso, ainda não era exigida sua aplicação. Nas outras quatro capitais, os entendimentos seguiam a decisão do STF, mas em nenhuma delas a decisão foi acolhida como consenso entre os profissionais entrevistados, cujos posicionamentos foram classificados em dois grupos. Para aqueles que concordam com a decisão, tornar a ação pública incondicionada significou retirar dos "ombros" da mulher a responsabilidade de escolher entre seguir ou não com uma ação judicial contra seus parceiros. O entendimento comum é que muitas mulheres nessa condição sofrem pressões por parte dos próprios 
agressores e de familiares para que desistam da queixa. Algumas sofrem ameaças, ficam expostas a novas agressões e não raro acabam voltando a viver na situação de violência sem perspectiva para sua solução. Como ação pública incondicionada, a partir do registro da ocorrência policial nos casos de lesão corporal, o inquérito policial é imediatamente instaurado e as manifestações da vítima quanto a querer ou não dar seguimento a essa ação não devem interromper o curso "natural" do inquérito policial e correspondente processo judicial até que se obtenha um desfecho judicial, seja ele de culpa ou inocência. Para os defensores dessa decisão do STF, não é apenas o caso individual que passa para a responsabilidade do Estado, mas é, também, uma forma de mostrar que a violência doméstica e familiar é um problema social e sua resolução é interesse da sociedade. Independentemente do rumo tomado pelas pessoas e por seu relacionamento - se reconciliação ou separação -, a violência praticada será processada e julgada para responsabilizar o agressor pelos atos que cometeu e para inibir novos comportamentos violentos.

Já entre aqueles que discordam da decisão do STF encontram-se opiniões que pautam por uma perspectiva de gênero e aqueles que se pautam pela visão mais tradicional do funcionamento das instituições. No primeiro grupo, estariam argumentos pela construção da autonomia da vítima e a valorização de sua vontade que deve ser ouvida e fortalecida a partir do acesso à informação e a direitos:

Eu não gosto muito de tutelar os interesses da mulher, porque eu não acho a mulher incapaz de decidir. O que ela precisa ter é conhecimento das consequências pra ela saber se ela decide de uma forma ou se decide de outra, se ela quer seguir ou se ela não quer seguir... então eu não acho que cabe ao Estado...porque nós não estamos lidando com pessoas débeis, nós estamos lidando com pessoas que tem capacidade de responder diante do conhecimento que ela tenha das consequências de sua decisão. [...] nós dos serviços é que precisamos preparar essa mulher...a solução não tem que ser dada pelo jurídico. (Defensora Pública)

Essa opinião é compartilhada de maneira mais ou menos enfática por policiais, defensoras e alguns juízes para os quais a prática mostra que muitas mulheres "desistem” da ação judicial, dificultando o trabalho e a conclusão dos processos.

Essa desistência alimenta as opiniões do segundo grupo de opositores da decisão do STF, que se preocupam com o volume de trabalho que é gerado para os serviços e profissionais sem que possam ver seu resultado. Para muitos dessas(es) profissionais, o atendimento ainda se pauta por uma visão preconceituosa e discriminatória contra as mulheres que são descritas como as principais responsáveis pela demora na conclusão dos inquéritos policiais e na deficiência das provas que são produzidas. Nas entrevistas, além de afirmações de que as mulheres "mentem”, "inventam histórias”, foram também 
mencionadas as situações em que elas "somem", "escondem os agressores" e não respondem às intimações policiais e judiciais, não realizam os laudos médicos e não colaboram com a identificação de testemunhas.

Ainda que seja possível aferir a veracidade dessas situações no dia a dia de delegacias e fóruns, e elas possam também ser verificadas na leitura de inquéritos policiais e processos judiciais quando são registradas as várias tentativas realizadas por investigadores e oficiais de justiça para a localização das partes, é bem verdade também que são situações que não podem ser generalizadas a partir do pressuposto de que todas as mulheres desejam desistir da intervenção judicial, assim como não se pode reduzir esse comportamento a um simples "querer", entendido como uma vontade racionalmente orientada das mulheres que agem de forma calculada no acionamento e abandono da via judicial para a resolução da situação de violência na qual se encontram.

Esse querer ou vontade que é identificado pelos operadores do direito é reflexo, na realidade, de um conjunto de sentimentos - como medo, dúvida, insegurança - e circunstâncias - pressão de familiares e do próprio agressor, a dependência emocional, econômica -, além de outros fatores sociais, como a própria dificuldade que algumas mulheres enfrentam em ficar sozinhas em comunidades onde há muita violência no entorno (JUBB, 2010; PASINATO, 2012).

Suspeitar da ocorrência da violência e desrespeitar a mulher que tenta reivindicar seus direitos significa mover a mulher do lugar de sujeito de direitos que ela deve ocupar, fortalecida e capaz de tomar decisões. A pouca informação que conseguem captar e que incorporam às narrativas que apresentam nos serviços policiais não é reconhecida como parte de seu processo de empoderamento, mas como usurpação de um discurso (de um lugar e de um direito) que não é reconhecido como seu.

Ao analisar as percepções que foram compartilhadas por alguns profissionais de todas as capitais, observa-se que são poucas mudanças na compreensão do que é a violência baseada no gênero e que essas mudanças são individuais e resultado da busca particular de alguns(mas) profissionais diretamente envolvidos com a aplicação da lei e que foram sensibilizado(a)s para o tema. Encontra-se também que essa atuação sensível ocorre num ambiente de resistência, de instituições que não se prepararam para cumprir com seus novos mandatos e nas quais o machismo institucionalizado bloqueia o avanço e a incorporação de políticas de gênero que contribuam para a promoção dos direitos das mulheres e a igualdade de gênero.

Como resultado, a culpa recai sobre as mulheres que são acusadas de fazer um uso inadequado da lei, não sabem o que querem e agem com o intuito de prejudicar seus agressores. A afirmação de que as mulheres "mentem" é reveladora do tipo de atendimento que elas estão recebendo. Se a versão que apresentam é colocada em dúvida desde seu primeiro contato com a instituição, é difícil acreditar que o atendimento será “digno, respeitoso, acolhedor e humanizado”, como se encontra preconizado na 
Norma Técnica das DEAMs (SPM, 2010) e nos manuais de atendimento a mulheres em situação de violência (UNODC, 2011).

Deslocar o foco para o comportamento das mulheres contribui para desviar a atenção daquele que é o principal problema a ser enfrentado para assegurar o acesso das mulheres à justiça: como modernizar o sistema de justiça para que ele possa dar respostas efetivas para as mulheres, reformulando seus procedimentos, criando novas dinâmicas para os fluxos de documentos e pessoas entre as diferentes instituições que o formam, promovendo a articulação entre o sistema de justiça-segurança e os demais serviços que devem compor a rede de atendimento intersetorial e multidisciplinar?

\section{CONSIDERAÇÕES FINAIS}

A pesquisa "Violência contra a mulher e acesso à justiça" teve como objetivo conhecer as condições de aplicação da Lei Maria da Penha e os obstáculos para a universalização do acesso à justiça para as mulheres em situação de violência doméstica e familiar. Embora as cinco capitais representem realidades diversificadas, observou-se que as dificuldades são bastante comuns e resultam sobretudo da falta de investimento público para a criação das estruturas necessárias e a formação de recursos humanos suficientes e adequadamente capacitados para o atendimento da violência baseada no gênero. A qualificação dos profissionais é condição para o bom atendimento que irão oferecer e também um dos critérios para definir a especialização dos serviços. Não se trata apenas de ter bom domínio sobre os procedimentos administrativos, ou das técnicas de atendimento ao público, mas conhecer e compreender as especificidades da violência baseada em gênero. Compreender essas características permite ajudar as mulheres a superar os obstáculos que precisam enfrentar. A falta de especialização dos profissionais é um obstáculo ao acesso das mulheres à justiça e pode ocorrer e se repetir em diferentes momentos do atendimento - desde o primeiro balcão, onde a mulher solicita informações, até decisão judicial.

A falta de protocolos para o atendimento e os encaminhamentos são também obstáculos que foram identificados nesta pesquisa e confirmam os resultados de estudos anteriores. Sem protocolos, os atendimentos não são orientados por regras institucionais que devem ser aplicadas por todos os profissionais de acordo com as situações que se apresentem. Na prática, esses atendimentos e encaminhamentos ocorrem de acordo com o "perfil" do profissional (da delegada titular, do juiz etc., e de cada um dos membros de suas equipes), fazendo com que o acesso das mulheres aos seus direitos seja condicionado por uma maior ou menor sensibilidade do profissional e conhecimento sobre a gravidade do problema da violência baseada em gênero. 


\section{NOTAS}

* Este artigo é uma versão sintetizada do relatório final da pesquisa Violência Contra a Mulher e Acesso à Justiça. Estudo comparativo sobre a aplicação da Lei Maria da Penha em cinco capitais, desenvolvido pela CEPIA entre outubro de 2012 e março de 2013, com apoio financeiro da Fundação Ford. A equipe de pesquisa foi composta por: Terezinha Vergo, Domitila Andrade, Fernando de Barros Jr., Rosana Heringer, Mariana Barsted, Telma Rosenail, Natália Silveira e Wânia Pasinato. O uso do material foi autorizado por Leila Linhares Barsted e Jacqueline Pitanguy, Diretoras Executivas da CEPIA, a quem agradeço a autorização. O relatório final encontra-se disponível em:

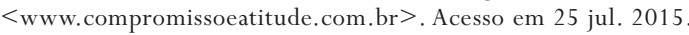

1 Para exemplos, ver: <http://www.spm.gov.br/assuntos/estatisticas-de-genero>. Acesso em 30 jun. 2015.

2 Mais informações sobre o estudo encontram-se no relatório final da pesquisa disponível em: <http://www. compromissoeatitude.org.br/wp-content/uploads/2013/11/Pesquisa-Violencia-Contra-a-Mulher-e-Acesso-aJustica_SumarioExecutivo.pdf $>$. Acesso em 25 jul. 2015.

3 "O ponto de partida para elaboração dos indicadores foi a leitura e análise da Lei Maria da Penha em sua versão comentada (CAMPOS, 2011), para identificação de suas principais medidas e seus aspectos mais polêmicos. Foram também revisados relatórios que avaliam o cumprimento dos acordos internacionais pelos governos, em especial os documentos produzidos para o monitoramento da Convenção de Belém do Pará (OEA - MESECVI 2008 e 2012; CIDH, 2007) e outros que abordam o acesso à justiça para mulheres (UNWomen, 2011) e a metodologia de monitoramento de leis para enfrentamento da violência contra as mulheres (OPAS, 2004)” (CEPIA, 2013, p. 21). Os indicadores foram organizados em quatro grupos: o primeiro sobre a institucionalidade dos órgãos encarregados da aplicação da LMP, sendo considerados: a existência de órgão de gestão/coordenação das políticas de gênero e aplicação da LMP na Polícia Civil, no Ministério Público, na Defensoria Pública e Tribunal de Justiça; a institucionalidade e a transversalidade gênero nas políticas institucionais, a articulação institucional, participação política, intersetorialidade e articulação na rede; o segundo tratou da existência de serviços especializados com indicadores sobre: a existência de serviços/instâncias especializadas nos setores de segurança e justiça para aplicação da Lei Maria da Penha, incluindo as equipes multidisciplinares e os serviços de responsabilização do agressor, a adequação normativa, de infraestrutura e de procedimentos dos serviços às atribuições previstas na LMP, a formação e especialização dos profissionais envolvidos no atendimento, na aplicação da lei e na gestão dos serviços considerando; o terceiro grupo tratou da aplicabilidade da Lei Maria da Penha segundo a estrutura dos serviços e sua forma de organização administrativa, política e burocrática; e o quarto grupo tratou da aplicabilidade da lei segundo a percepção dos operadores do direito sobre a violência contra a mulher, os dispositivos legais e sobre a adequação das respostas institucionais e suas percepções sobre a violência contra a mulher, as respostas intersetoriais, a rede de atendimento, as políticas e serviços para aplicação das medidas de assistência previstas na LMP (art. $9^{\circ}$ ). Detalhes encontram-se disponíveis no relatório final.

4 Segundo as orientações da SPM, essa rede é composta de delegacia especializada de atendimento à mulher (DEAMs), juizado/vara de violência doméstica e familiar, promotorias e defensorias especializadas, centros de referência, casas abrigo e serviços de saúde. Também contam com organismos de políticas para mulheres (secretarias, coordenadorias etc.) e conselhos dos direitos da mulher.

5 Essas experiências consistem em programas, produção de materiais didáticos, protocolos e sistemas de informações que contribuem para a melhor aplicação da legislação. O uso da expressão "práticas promissoras" para designar essas experiências, aplica-se para aqueles exemplos considerados adequados ao objetivo de ampliar e garantir o acesso à justiça e a direitos para as mulheres em situação de violência doméstica e familiar (PASINATO, 2011, p. 123).

6 Detalhes sobre o perfil dos profissionais entrevistados são omitidos neste artigo pela limitação de espaço e estão disponíveis no relatório final da pesquisa, cujo acesso encontra-se disponível na nota introdutória deste artigo.

7 A dificuldade na realização dos estudos de caso é a rapidez com que os cenários se modificam pela edição de novas normas institucionais ou pela rotatividade de profissionais que coordenam os serviços. Não é incomum que experiências aparentemente promissoras se desarticulem nessas mudanças. Sempre que possível, procura-se registrar essas mudanças nos cenários observados. 
8 Os principais estudos utilizados como referência foram OBSERVE, 2010 e 2011; PASINATO, 2012. Entre outros que são mencionados ao longo do relatório.

9 Estudos já mostraram o peso dos condicionantes culturais dos agentes públicos e que devem ser considerados quando a vítima é mulher. A esse respeito ver HERMANN; BARSTED, 1995.

10 Em 2014, a CEPIA realizou pesquisa comparativa em três capitais sobre a aplicação das medidas protetivas. O estudo "Medidas protetivas às mulheres em situação de violência" foi realizado com financiamento da SENASP/PNUD no âmbito da $3^{a}$ edição do Pensando a Segurança Pública (relatório não publicado).

11 Entre as cinco capitais no momento dos estudos de caso, a única iniciativa para esse acompanhamento foi encontrada em Porto Alegre, onde funciona a Patrulha da Lei Maria da Penha, um projeto da Brigada Militar. Em 2014, um projeto semelhante foi implementado em São Paulo, resultado da parceria entre a Guarda Municipal e o Ministério Público. Em 2015, Salvador também ganhou um serviço dessa natureza.

12 No final de 2013, um projeto criado pela juíza o I Juizado de Violência Doméstica e Familiar da capital promoveu celeridade nesse encaminhamento, possibilitando que as mulheres em situação de risco recebam as medidas protetivas no mesmo dia de sua solicitação. Trata-se do Projeto Violeta, premiado em 2014 no Prêmio Innovare. Disponível em: <http://www.premioinnovare.com.br/praticas/projeto-violeta-20140527232412433005/>. Acesso em 9 nov. 2015.

\section{REFERÊNCIAS BIBLIOGRÁFICAS}

ARTIGO 19. Violência contra a mulher no Brasil. Acesso à informação e políticas públicas. 2015. São Paulo: Artigo 19, 2015.

BARSTED, Leila Linhares. Lei Maria da Penha. Uma experiência bem sucedida de Advocacy. In: CAMPOS, C. (org.). Lei Maria da Penha comentada na perspectiva jurídico-feminista. Rio de Janeiro: Lumen Juris, 2011. . O progresso das mulheres no enfrentamento da violência. In: BARSTED, Leila Linhares; PITANGUY, Jacqueline (orgs.) O progresso das mulheres no Brasil 2003-2010. Rio de Janeiro: CEPIA/UNWomen, 2011.

Violência contra a mulher e cidadania: uma avaliação das políticas públicas. Rio de Janeiro: CEPIA. Cadernos CEPIA, ano 1, n. 1, 1994.

; PITANGUY, Jacqueline (orgs.) O progresso das mulheres no Brasil 2003-2010. Rio de Janeiro: CEPIA/UNWomen, 2011.

CAMPOS, Carmen Hein de; CARVALHO, Salo de. Tensões atuais entre a criminologia feminista e a criminologia crítica: a experiência brasileira. In: CAMPOS, Carmen H. de (org.). Lei Maria da Penha sob a perspectiva feminista. Rio de Janeiro: Lumen Juris, 2011.

(org.). Lei Maria da Penha sob a perspectiva feminista. Rio de Janeiro: Lumen Juris, 2011.

CAPPELlETTI, Mauro; GARTH, Bryant. Acesso à justiça. Porto Alegre: Safe, 1988.

DATASENADO. Violência doméstica e familiar contra a mulher. Brasília: Senado Federal/Secretaria de Transparência, mar. 2013.

HERMANN, Jacqueline; BARSTED, Leila Linhares. O Judiciário e a violência contra a mulher - A ordem legal e a (des)ordem familiar. Rio de Janeiro: CEPIA, 1995.

IZUMINO, Wânia Pasinato. Justiça para todos: Juizados Especiais Criminais e a violência de gênero. Tese de Doutorado. Depto. Sociologia/FFLCH. Universidade de São Paulo, 2003.

JUBB, Nadine et al. Delegacias da mulher na América Latina. Uma porta para deter a violência e ter acesso à Justiça. Quito: Ceplaes/Trama, 2010.

LIMA, Fausto Rodrigues de. Dos procedimentos - artigos 13 a 17. In: CAMPOS, C. (org.). Lei Maria da Penha comentada na perspectiva jurídico-feminista. Rio de Janeiro: Lumen Juris, 2011.

MARTINS, Ana Paula Antunes; CERQUEIRA, Daniel; MATOS, Maria Vieira Martins. A institucionalização das políticas públicas de enfrentamento à violência contra as mulheres no Brasil (versão preliminar). Nota Técnica n. 13. Brasília: IPEA, 2015. 
MILOSAVLJEVIC, Vivian. Estadísticas para la equidad de género: Magnitudes y tendencias en América Latina. Santiago: Comisión Económica para América Latina y el Caribe (CEPAL) y el Fondo de Desarrollo de las Naciones Unidas para la Mujer (UNIFEM), 2007.

NORMA TÉCNICA de Padronização das delegacias especializadas de atendimento às mulheres - DEAMs. Brasília: SPM/SENASP/UNODC, 2010.

OBSERVE. Condições para aplicação da Lei n. 11.340/2006 (Lei Maria da Penha) nas Delegacias

Especializadas de Atendimento à Mulher (DEAMs) e nos Juizados de Violência Doméstica e Familiar nas capitais e no Distrito Federal. Salvador: Observe/Observatório da Lei Maria da Penha, 2010.

. Identificando entraves na articulação dos serviços de atendimento às mulheres vítimas de violência doméstica e familiar em cinco capitais. Projeto Observe/UNIFEM. Salvador: Observe/Observatório da Lei Maria da Penha, 2011.

PANDJIARJIAN, Valéria. Balanço de 25 anos da legislação sobre a violência contra as mulheres no Brasil. In: DINIZ, Simone G; SILVEIRA, Lenira P.; LIZ, Mirian A. (org.). Vinte e cinco anos de respostas brasileiras em violência contra a mulher (1980-2005). Alcances e limites. São Paulo: Coletivo Feminista Sexualidade e Saúde, 2006.

PASINATO, Wânia. Acesso à justiça e violência contra a mulher em Belo Horizonte. São Paulo:

Annablume/FAPESP, 2012.

. Avanços e obstáculos na implementação da Lei Maria da Penha. In: CAMPOS, C. (org.). Lei Maria da Penha comentada na perspectiva jurídico-feminista. Rio de Janeiro: Lumen Juris, 2011.

Violência contra as mulheres e legislação especial, ter ou não ter? Eis uma questão. Revista

Brasileira de Ciências Criminais, n. 70, São Paulo: IBCCRIM. jan.-fev. 2008.

RODRIGUES, Almira; CORTES, Iáris (org.). Os direitos das mulheres na legislação brasileira pós-constituinte.

Brasília: Letras Livres, 2006.

SOARES, Barbara Musumeci. A antropologia no executivo: limites e perspectivas. In: CORRÊA, Mariza

(org.). Gênero \& cidadania. Campinas: PAGU/Núcleo de Estudos de Gênero/UNICAMP, 2002.

SOUZA SANTOS, Boaventura de et al. Os tribunais nas sociedades contemporâneas: o caso português. Porto: Afrontamento, 1996.

SPM. Rede de enfrentamento à violência contra as mulheres. Brasília: Secretaria de Enfrentamento à

Violência/SPM, 2010.

UNODC. Respostas para a violência baseada em gênero no Cone Sul: avanços, desafios e experiências regionais.

Relatório Regional. DF: UNODC/UNIFEM, 2011.

UNWomen. El progreso de las mujeres en el mundo. 2011-2012. En busca de la Justicia. New York: UNWomen, 2011.

\title{
Wânia Pasinato
}

\author{
Rio de Janeiro - RJ - Brasil \\ waniapasinatolagmail.com
}

SocióLoga.

MESTRE E DOUTORA EM SOCIOLOGIA (USP). Pós-doutora no Núcleo de Estudos de Gênero -

PAGU (UNICAMP).

Consultora da CEPIA - Cidadania, Estudo, Pesquisa, INFORMACC̆O E ACC̃ão (RJ) E DA ONU MULHERES, ONDE COORDENA AS AC̣ŌES DE ENFRENTAMENTO ÀS MORTES VIOLENTAS DE MULHERES POR RAZÕES DE GÊNERO (FEMINICÍDIOS). 
